This is an author produced version of a paper published in Biochemical and Biophysical Research Communications. This paper has been peerreviewed but does not include the final publisher proof-corrections or journal pagination.

Citation for the published paper:

Grethe, Simone and Coltella, Nadia and Di Renzo, Maria Flavia and Porn-Ares, M Isabella.

"p38 MAPK downregulates phosphorylation of Bad in doxorubicininduced endothelial apoptosis"

Biochemical and Biophysical Research Communications, 2006, Vol: 347, Issue: 3 pp. 781-90.

http://dx.doi.org/10.1016/j.bbrc.2006.06.159

Access to the published version may require journal subscription.

Published with permission from: Elsevier 


\section{p38 MAPK Downregulates Phosphorylation of Bad in}

\section{Doxorubicin-Induced Endothelial Apoptosis}

Simone Grethe, ${ }^{\mathrm{a}}$ Nadia Coltella, ${ }^{\mathrm{b}}$ Maria Flavia Di Renzo, ${ }^{\mathrm{b}}$ M. Isabella Pörn-Ares ${ }^{\mathrm{a}}{ }^{*}$

${ }^{a}$ Lund University, Division of Experimental Pathology, Department of Laboratory Medicine, University Hospital MAS, Malmö, Sweden

${ }^{b}$ Laboratory of Cancer Genetics, Institute for Cancer Research and Treatment (ICRR),

Candiolo (TO), Italy

*Corresponding author. Present address: Institute of Biomedicine/ Biochemistry, Helsinki University, Biomedicum, Haartmaninkatu 8, FI-00014 Helsinki, Finland. Fax: +358 9191 25 444. E-mail address: isabella.ares@ @elsinki.fi 


\begin{abstract}
Doxorubicin is the anthracycline with the widest spectrum of antitumor activity, and it has been shown that the antitumor activity is mediated in vivo by selective triggering of apoptosis in proliferating endothelial cells. We studied cultured human endothelial cells and observed that doxorubicin-induced apoptosis was mediated by p38 mitogen-activated protein kinase (MAPK). Doxorubicin-provoked apoptosis was significantly inhibited by expression of dominant negative p38 MAPK or pharmacological inhibition with SB203580. Furthermore, blocking phosphatidylinositol-3-kinase/Akt signaling significantly increased doxorubicin-induced caspase- 3 activity and cell death, indicating that Akt is a survival factor in this system. Notably, we also found that doxorubicin-provoked apoptosis included p38 MAPK-mediated inhibition of Akt and Bad phosphorylation. Furthermore, doxorubicinstimulated phosphorylation of Bad in cells expressing dominant negative p38 MAPK was impeded by the inhibition of PI3-K. In addition to the impact on Bad phosphorylation, doxorubicin-treatment caused p38 MAPK-dependent downregulation of Bcl-xL protein.
\end{abstract}

Keywords: doxorubicin; endothelial cells; p38 MAPK; Bad; Akt 


\section{Introduction}

Doxorubicin is the anthracycline with the widest spectrum of antitumor activity [1], but the clinical efficacy of this drug is limited due to severe cardiotoxicity in adult and pediatric patients [2]. It has been shown that doxorubicin-induced apoptosis in endothelial cells and cardiomyocytes involves formation of hydrogen peroxide [3,4], and it has also been reported that antioxidant treatment exerts cardioprotective effects in cancer patients receiving doxorubicin chemotherapy [5]. It was recently demonstrated that the antitumoral influence of doxorubicin can be mediated in two ways: either through targeting of the tumor endothelium or by destruction of both the tumor endothelium and tumor cells [6-8]. Research has revealed that both the cardiotoxicity $[9,10]$ and the antitumoral effect of doxorubicin involve endothelial apoptosis, thus it is highly important to further elucidate the underlying signaling mechanisms in order to gain novel information about how to selectively regulate these two types of doxorubicin-induced endothelial cell death.

The MAPK family consists of extracellular signal-regulated kinase (ERK) 1 and 2, Jun $\mathrm{N}$-terminal kinase (JNK), and p38 MAPK, which are known to mediate many of the processes associated with cell growth, survival, and death. JNK and p38 MAPK are stimulated by stress, ultraviolet light, heat, osmotic shock, and inflammatory cytokines. In previous studies $[11,12]$ we found that TNF-induced endothelial cell apoptosis requires p38 MAPK activity, which regulates the balance of Bcl-2 proteins in that system. The ERK pathway is initiated by mitogenic stimuli, such as growth factors, cytokines, and phorbol esters, and it plays a major role in regulating cell growth and differentiation [13]. However, ERK signaling has been suggested to be proapoptotic in cells undergoing doxorubicininduced apoptosis [14-16].

Phosphatidylinositol 3-kinase (PI3-K)/Akt is a major cell survival pathway that has been extensively studied. Direct binding of the PH domain of Akt to PtdIns $(3,4,5) \mathrm{P}_{3}$ permits 
phosphorylation of Akt by a phosphoinositide-dependent kinase (PDK1) at Thr308 [17]. Full activation of Akt requires further phosphorylation at Ser473, which has been suggested to occur via autophosphorylation [18] or through phosphorylation induced by integrinlinked kinase (ILK) [19]. Activated Akt regulates survival by phosphorylating numerous cellular proteins, such as caspase-9 [20], Bad [21], the forkhead family of transcription factors [22], GSK-3 $\beta$ [23], and NF- $\kappa B$ [24]. PI3-K/Akt mediates survival in a variety of cell types, including endothelial cells $[16,25]$, and there is evidence that sustained activation of Akt suppresses doxorubicin-induced apoptosis in gastric adenocarcinoma [26].

Members of the Bcl-2 family are key regulators of apoptosis that include both antiapoptotic proteins (e.g., Bcl-2, Bcl-xL, Mcl-1, and A1) and pro-apoptotic proteins (e.g., Bak, Bax, Bad, and Bid). Under normal conditions, Bad is phosphorylated and sequestered in the cytosol by 14-3-3 protein [27]. Upon dephosphorylation, Bad translocates to the mitochondria, where it associates primarily with Bcl-xL but also with Bcl-2, and thereby promotes apoptosis [28,29]. Cytokine-dependent phosphorylation of Bad has been reported to involve several kinases, such as Akt, protein kinase A (PKA), RSK1 (p90 ribosomal S6 kinase1), p70S6 kinase, and PAK1 [21,30-33].

Relatively little is known about the signaling pathways in doxorubicin-provoked endothelial apoptosis, thus our objective was to investigate the role of p38 MAPK and Bcl-2 proteins in such induced cell death. Our results suggest that p38 MAPK plays a novel role in this context by downregulating the Bcl-xL protein and inhibiting phosphorylation of Bad in a PI3K/Akt-dependent manner. 


\section{Materials and methods}

Antibodies and reagents. The following antibodies, reagents, and equipment were used in the present study (suppliers indicated within parentheses): doxorubicin (Adriamycin; Pharmacia, Stockholm, Sweden); anti- $\alpha$-tubulin Ab (Oncogene Research Products, Boston, MA); Asp-Glu-Val-Asp-aminomethylcoumarin (DEVD-amc), and anti-Akt pAb (Upstate Biotechnology, Lake Placid, NY); SB203580 (inhibitor of $\alpha$ and $\beta$ isoforms of p38 MAPK), LY294002 (PI3-K inhibitor), and Nonidet P-40 (Calbiochem, La Jolla, CA); anti-Bcl-xL pAb and an enhanced chemiluminescence (ECL) kit (Santa Cruz Biotechnology, Inc., Santa Cruz, CA); $\mathrm{NaVO}_{4}$ (ICN Pharmaceuticals, Inc., Costa Mesa, CA); leupeptin and Pefabloc SC (Roche Diagnostics, Mannheim, Germany); Coomassie Plus Protein Assay Reagent (Pierce, Rockford, IL); anti-PARP mAb (BIOMOL Research Laboratories, Plymouth Meeting, PA); anti-phospho-p38 MAPK pAb (detects all isoforms of p38 MAPK that have been activated by dual phosphorylation at Thr180 and Tyr182), anti-p38 MAPK pAb (recognizes p38 $\alpha$ MAPK), anti-phospho- JNK pAb, anti-JNK pAb, anti-phospho-ERK pAb, anti-ERK pAb, anti-phospho Ser473 Akt pAb, anti-phospho-serine $112 \mathrm{Bad}$ mAb, anti-Bad pAb, PD98059 (MEK1/2 inhibitor) and SP600125 (JNK inhibitor), (Cell Signaling Technology, Beverly, MA); trypan blue (Invitrogen, Paisley, UK); reagents and equipment for SDS polyacrylamide gel electrophoresis and a Fluor-S MultiImager (Bio-Rad, Rockford, IL). All other reagents were purchased from Sigma Chemicals (St. Louis, MO), unless otherwise stated.

Cell culture and inhibitor experiments. The permanent cell line EA.hy926 derived from human endothelium [34] was maintained in Dulbecco's Modified Eagle's Medium supplemented with $2 \mathrm{mM}$ L-glutamine, $50 \mathrm{IU} / \mathrm{ml}$ penicillin-streptomycin (all from 
Invitrogen), and 10\% heat-inactivated fetal bovine serum (PAA Laboratories, Linz, Austria). The cells were incubated at $37^{\circ} \mathrm{C}$ in a humidified $5 \% \mathrm{CO}_{2}$ atmosphere, and they were subcultured every five days in trypsin-EDTA solution for endothelial cells. For experiments, cells were cultured to $70 \%$ confluency, because we found that doxorubicin triggered apoptosis in proliferating cells, but had no effect on confluent cells (data not shown), which agrees with the selective effect of this drug observed by Lorenzo and coworkers [35]. In inhibitor experiments, cells were pre-treated for $1 \mathrm{~h}$ with one of the following: SB203580 (5 $\mu \mathrm{M})$, PD98059 (25 $\mu \mathrm{M})$, SP600125 (10 $\mu \mathrm{M})$, or LY294002 (10 $\mu \mathrm{M})$. The respective inhibitors were also present during subsequent exposure to doxorubicin.

Plasmids. Lentiviral vectors were generated by transient transfection performed as described by Follenzi et al. [36] using the three-plasmid expression system comprising the following: the packaging plasmid, $\mathrm{pCMV} \Delta \mathrm{R} 8.74$, designed to provide the HIV proteins needed to produce the virus particle; the envelope-coding plasmid pMD.G, for pseudotyping the virion with VSV-G; and the self-inactivating (SIN) transfer vector plasmid pRRL.sin.PPT.hCMV.Flag-p38 $(\mathrm{AF})$.pre. The transfer vector plasmid pRRL.sin.PPT.hCMV.Flag-p38a(AF) was obtained by substituting the luciferase reporter gene fragment in the pRRL.sin.PPT.hCMV.Luci.pre plasmid with the cDNA coding for a dominant negative Flag tagged p38 $\alpha$ containing T180A and Y182F amino acid substitutions [37] from the mammalian expression vector pcDNA3. The pRRL.sin.PPT.hCMV.Luci.pre plasmid was digested using XbaI enzyme and then blunted with Klenow enzyme and dephosphorylated with SAP enzyme, and it was subsequently ligated with the fragment Flag-p38 $\alpha(\mathrm{AF})$ from the digestion and blunting of pcDNA 3 with HindIII-XbaI. The 
transfer vector pRRL.sin.PPT.Ecadpr.Luciferase.pre containing wild-type E-cadherin promoter was used as control vector [38].

Flow cytometric analysis of $L V$-transduced cells. To determine the percentage of EA.hy926 cells expressing DNp38, EC ${ }^{\mathrm{DNp} 38}$ cells were analyzed using flow cytometry (FACSCalibur, Becton Dickinson Immunocytometry Systems, San Jose, CA). Briefly, cells were fixed and permeabilized using a Fix and Perm Kit (Caltag Laboratories, Burlingame, CA) according to the manufacturer's instructions. Expression of intracellular FLAG was determined by analyzing indirect immunofluorescence with a primary unconjugated mAb against FLAG (IgG1; Stratagene, La Jolla, CA) and a PE-conjugated secondary goat pAb against murine IgG1 (Southern Biotechnology Associates Birmingham, AL).

Western blot analysis. Cells were incubated in 60-mm culture dishes under various conditions, after which cells were lysed and proteins were analyzed on western blots as described previously [12].

Fluorometric assays for caspase-3 activity. Caspase-3 activity was analyzed by fluorescence spectrophotometry, using the fluorogenic peptide DEVD-amc as a substrate. Cells were treated as indicated for $21 \mathrm{~h}$, after which adherent cells were harvested on ice by scraping them into $300 \mu \mathrm{l}$ of caspase lysis buffer $\left(10 \mathrm{mM}\right.$ Tris- $\mathrm{HCl}, 10 \mathrm{mM} \mathrm{NaH} \mathrm{PO}_{4} / \mathrm{Na}_{2} \mathrm{HPO}_{4}[\mathrm{pH}$ 7.5], $130 \mathrm{mM} \mathrm{NaCl}, 0.1 \%$ Triton-X-100, and $10 \mathrm{mM} \mathrm{NaPP}$ ); floating cells were collected, pelleted, and pooled with the lysate. The assay was performed as decribed previously [12]. Analysis of cytotoxicity. Cells were incubated in 60-mm culture dishes and treated as indicated and then trypsinized. Floating cells were collected, pelleted, and pooled with 
trypsinized cells, and viability was assessed by trypan blue exclusion. Briefly, $10 \mu \mathrm{l}$ of cell suspension maintained in culture medium, was combined with $90 \mu 1$ of $0.4 \%$ sterile-filtered trypan blue, after which the cells were counted using a hemacytometer.

Statistical evaluations. All data are expressed as means $\pm \operatorname{SD}(n<5)$ or SEM $(n \geq 5)$, and Student's $t$ test was used for statistical analysis of the differences $\left({ }^{*} \mathrm{p}<0.05\right.$, **p $<0.01$, $* * * \mathrm{p}<0.001)$. 


\section{Results}

Expression of dominant negative p38 MAPK inhibits doxorubicin-induced endothelial apoptosis

It is known that doxorubicin treatment of cultured cells leads to production of reactive oxygen species (ROS) [39, 40], and that oxidative stress activates p38 MAPK [41], thus we wanted to elucidate the role of p38 MAPK in doxorubicin-induced apoptosis. To this end, we used lentiviral transduction of EA.hy926 cells to express a dominant negative mutant Flag-p38 $\alpha$ MAPK harboring T180A and Y182 F amino acid substitutions [37]. Use of lentiviral vectors ensures the stable and sustained expression of transgenes in any cell type, because even non-dividing cells are transduced, and transgenes are integrated in multiple and different DNA regions in each cell. Furthermore, an internal promoter included in the transgene cassette drives transgene expression, which is not influenced by the integration site. Therefore, we were able to compare the bulk unselected EA.hy926 cell population expressing the DNp38 variant $\left(\mathrm{EC}^{\mathrm{DNp} 38}\right)$ with EA.hy926 cells that were either not transduced $\left(\mathrm{EC}^{\mathrm{WT}}\right)$ or were transduced with a control vector $\left(\mathrm{EC}^{\mathrm{CV}}\right)$ containing a nonexpressed cassette. FACS analysis showed that $60 \%$ of the EC ${ }^{\mathrm{DNp} 38}$ expressed the pDNp38 (data not shown). Treatment with clinically relevant concentrations of doxorubicin resulted in similar concentration-dependent activation of caspase-3 in $\mathrm{EC}^{\mathrm{WT}}$ and $\mathrm{EC}^{\mathrm{CV}}$, as indicated by cleavage of poly(ADP-ribose) polymerase (PARP) (Fig. 1A and B). Notably, expression of DNp38 in the EA.hy926 cells reduced the doxorubicin-provoked activation of caspase-3 (measured as DEVDase activity) by $60 \%$ as compared to $\mathrm{EC}^{\mathrm{CV}}$ (Fig. 1C), and also decreased cell death caused by the drug by $57 \%$ (Fig. 1D). Since $60 \%$ of EC ${ }^{\mathrm{DNp} 38}$ cells expressed DNp38 MAPK, this means that virtually all DNp38-expressing cells were 
resistant to death induced by doxorubicin. These findings indicate that p38 MAPK plays a crucial role in doxorubicin-induced endothelial apoptosis.

Activation of endogenous p38 MAPK in endothelial cells undergoing doxorubicin-induced apoptosis

To further investigate the role of p38 MAPK in doxorubicin-induced apoptosis, we used an anti-phospho-p38 MAPK Ab to detect activated endogenous p38 MAPK on Western blots. We found that activation of p38 MAPK in wild type EA.hy926 cells occurred early (after 30 min) during incubation with $0.5 \mu \mathrm{g} / \mathrm{ml}$ doxorubicin and was sustained for $24 \mathrm{~h}$ (data not shown). Moreover, the stimulation of p38 MAPK (Fig. 1E) was concentration-dependent, with a peak at $1 \mu \mathrm{g} / \mathrm{ml}$ doxorubicin. That finding agrees well with the concentration-related activation of caspase-3 and cleavage of PARP (Fig. 1A-C), and, notably, doxorubicininduced p38 MAPK phosphorylation preceded activation of caspase-3 and cell death (data not shown). These results underline the significance of p38 MAPK in doxorubicin-induced endothelial apoptosis.

\section{Pharmacological inhibition of p38 MAPK impedes doxorubicin-induced apoptosis}

To gain support for our results with $\mathrm{EC}^{\mathrm{DNp} 38}$ we treated endothelial cells with doxorubicin in combination with the inhibitor SB203580, which specifically targets the $\alpha$ - and $\beta$ - isoforms of p38 MAPK [42]. Such cotreatment reduced PARP cleavage (Fig. 2A) and DEVDase activity (Fig. 2B) by approximately 50\%, and similar results were obtained when analyzing proteolysis of procaspase-3 (data not shown). By comparison, untreated cells and cells exposed solely to SB203580 exhibited very little or no detectable caspase-3 activity (Fig. 2A and B). Cotreament with SB203580 also caused a 40\% decrease in cell death induced by doxorubicin (Fig. 2C). Together, these results indicate that pharmacological inhibition of 
p38 MAPK and transduction with DNp38 MAPK reduce doxorubicin-provoked apoptosis in similar ways.

Participation of other MAP kinases and Akt in doxorubicin-induced apoptosis

Our next objective was to investigate the roles of JNK, ERK, and PI3-K/Akt signaling in endothelial cells undergoing doxorubicin-induced apoptosis. We stimulated cells with doxorubicin $(0.5 \mu \mathrm{g} / \mathrm{ml})$ for $21 \mathrm{~h}$ in the presence or absence of PD98059 (MEK1/2 inhibitor), SP600125 (JNK inhibitor), or LY294002 (PI3-K inhibitor) and then analyzed caspase-3 (DEVDase) activity in cell lysates. Untreated cells and cells exposed solely to an inhibitor exhibited very little caspase-3 activity (Fig. 3A). Cotreatment with SP600125 reduced doxorubicin-induced caspase- 3 activity by $65 \%$ in $\mathrm{EC}^{\mathrm{WT}}$ and by $56 \%$ in $\mathrm{EC}^{\mathrm{DNp} 38}$ (Fig. 3A), which suggests that JNK promotes endothelial cell apoptosis caused by doxorubicin, in accordance with a recent report by Panaretakis and coworkers [43]. In addition, SP600125 exerted similar protective effects on $\mathrm{EC}^{\mathrm{WT}}$ and $\mathrm{EC}^{\mathrm{DNp} 38}$, which implies that JNK and p38 MAPK act via pro-apoptotic signaling pathways that are at least partly independent.

Several investigators $[25,44]$ have shown that ERK activity can act as a survival signal in endothelial apoptosis, and we recently observed that inhibition of ERK potentiated TNFinduced endothelial apoptosis [12]. However, in the present experiments, inhibition of the MEK-ERK pathway in $\mathrm{EC}^{\mathrm{WT}}$ decreased doxorubicin-induced caspase-3 activity by $73 \%$ and also curbed the cytotoxicity of the drug by $49 \%$, and the corresponding values for $\mathrm{EC}^{\mathrm{DNp} 38}$ were $56 \%$ and $58 \%$, respectively (Fig. 3B). These results suggest that ERK signaling is proapoptotic in doxorubicin-treated cells, which agrees with findings reported by other investigators [14-16]. It seems that this proapoptotic role of ERK is partly independent of the p38 MAPK pathway. 
Interestingly, using the inhibitor LY294002 to block the PI3-K/Akt pathway restored the caspase- 3 activity in doxorubicin-treated $\mathrm{EC}^{\mathrm{DNp} 38}$ to a level comparable or higher to that observed in $\mathrm{EC}^{\mathrm{WT}}$ exposed to doxorubicin (Fig. 3A). Moreover, LY294002 increased the cytotoxicity of doxorubicin to nearly the same levels in $\mathrm{EC}^{\mathrm{DNp} 38}$ and $\mathrm{EC}^{\mathrm{CV}}$ (44\% and $47 \%$, respectively; Fig. 3B).

In a previous study [12], we detected crosstalk between p38 MAPK and the MEK/ERK signaling pathway in TNF-induced endothelial apoptosis, thus in the current investigation we analyzed doxorubicin-induced activation of ERK in $\mathrm{EC}^{\mathrm{DNp} 38}$ and $\mathrm{EC}^{\mathrm{WT}}$ by Western blotting. The results show that doxorubicin treatment for $24 \mathrm{~h}$ caused similar concentrationdependent increases in ERK activity in $\mathrm{EC}^{\mathrm{CV}}$ and $\mathrm{EC}^{\mathrm{DNp} 38}$ (Fig. 3C). Furthermore, we did not detect any significant difference in JNK activity upon treatment of $\mathrm{EC}^{\mathrm{CV}}$ and $\mathrm{EC}^{\mathrm{DNp} 38}$ with increasing concentrations of doxorubicin (data not shown), which agrees with our observation that SP600125 had similar effects on apoptosis in the two cell sublines. Together, these findings imply that, in doxorubicin-induced endothelial cell apoptosis, PI3$\mathrm{K} /$ Akt is an important survival factor, whereas ERK and JNK seem to have proapoptotic functions.

p38 MAPK-mediated downregulation of Bcl-xL induced by doxorubicin In a previous investigation [11], we found that TNF-induced apoptosis in endothelial cells involved p38 MAPK-mediated phosphorylation and degradation of anti-apoptotic Bcl-xL. To determine whether 338 MAPK can regulate the levels of Bcl-xL protein during doxorubicin-induced apoptosis, we treated $\mathrm{EC}^{\mathrm{DNp} 38}$ and $\mathrm{EC}^{\mathrm{CV}}$ for $24 \mathrm{~h}$ with increasing concentrations of doxorubicin and then analyzed Bcl-xL in the cells by Western blotting. We found that treatment with doxorubicin significantly decreased the level of Bcl-xL in $\mathrm{EC}^{\mathrm{CV}}$, whereas the amounts of this protein in $\mathrm{EC}^{\mathrm{DNp} 38}$ remained stable upon exposure to 
different concentrations of the drug (Fig. 4A and B). These results indicate that doxorubicin induces p38 MAPK-dependent downregulation of Bcl-xL protein in endothelial cells.

Doxorubicin-induced p38 MAPK activation negatively regulates phosphorylation of Akt and Bad

We subsequently examined the effect of doxorubicin on phosphorylation of $\mathrm{Bad}$ in endothelial cells. Interestingly, upon treatment with the drug, Bad Ser112 phosphorylation was significantly increased in $\mathrm{EC}^{\mathrm{DNp} 38}$, but remained unchanged in $\mathrm{EC}^{\mathrm{CV}}$ (Fig. 5A). Considering our observation that doxorubicin-induced ERK activity displayed similar kinetics in $\mathrm{EC}^{\mathrm{DNp} 38}$ and $\mathrm{EC}^{\mathrm{CV}}$, and that $\mathrm{ERK}$ seems to play a proapoptotic role in this system, it is unlikely that the downstream target of ERK (RSK1) is involved in phosphorylation of Bad. Therefore, we next used an anti-phospho-Ser473 Akt Ab to study activation of Akt in $\mathrm{EC}^{\mathrm{DNp} 38}$ and $\mathrm{EC}^{\mathrm{CV}}$ exposed to increasing concentrations of doxorubicin. The results indicate that Akt activation was significantly elevated in $\mathrm{EC}^{\mathrm{DNp} 38}$ treated with $0.5 \mu \mathrm{g} / \mathrm{ml}$ doxorubicin, whereas the drug had no effect on Akt activity in $\mathrm{EC}^{\mathrm{CV}}$. Western blotting with a total Akt Ab showed that the levels of this protein remained stable (Fig. 5B). According to these observations, the $\mathrm{EC}^{\mathrm{DNp} 38}$ exhibited concurrent increases in phosphorylation of Akt and Bad in response to doxorubicin treatment, suggesting that p38 MAPK-mediated inhibition of Akt leads to activation of Bad during doxorubicin-induced apoptosis. To ascertain whether p38 MAPK-mediated regulation of Bad phosphorylation occurs via a PI3K-dependent pathway, we exposed cells to both doxorubicin and LY294002 for $18 \mathrm{~h}$ (Fig. 5C). This shorter treatment period was chosen because we had found that the inhibitor strongly increased caspase-3 activity and cell permeability after $21 \mathrm{~h}$ (Fig. 3A and B). LY294002 inhibited the doxorubicin-induced phosphorylation of Bad in $\mathrm{EC}^{\mathrm{DNp} 38}$ (Fig. 5C), 
suggesting the occurrence of doxorubicin-provoked, p38 MAPK-mediated inhibition of Akt signaling, which in turn blocked phosphorylation of Bad. 


\section{Discussion}

Doxorubicin is a major antitumor agent used to treat a variety of human cancers [1]. This drug induces apoptosis in endothelial cells, which is a desirable event that leads to the regression of tumor vessels. However, the cardiotoxicity of doxorubicin also involves endothelial cell apoptosis, which is an undesirable effect. Consequently, it is essential to unravel the endothelial signaling events that mediate doxorubicin-induced apoptosis.

We provide several lines of evidence supporting an important role for p38 MAPK in doxorubicin-induced endothelial apoptosis. First, we found that expression of DNp38 MAPK and pharmacological inhibition of p38 MAPK with SB203580 led to severe attenuation of both the caspase-3 activating and cytotoxic effects of doxorubicin. Second, stimulation of $\mathrm{p} 38$ MAPK by doxorubicin preceded caspase- 3 activation by this drug and occurred in a concentration- and time-dependent manner. These findings agree well with recent studies showing that p38 MAPK is activated by doxorubicin and is required for doxorubicin-induced apoptosis in fibroblasts and cardiomyocytes [45-47], although possible involvement of Bcl-2 proteins was not considered in those investigations. Nevertheless, other researchers [48] found no change in p38 MAPK activity in breast cancer cells treated with doxorubicin, and it has been suggested that p38 MAPK protects lung cancer cells from apoptosis caused by doxorubicin [49]. Our data show that p38 MAPK mediates doxorubicin-induced endothelial apoptosis by inhibiting phosphorylation of Bad in a PI3K/Akt-dependent manner and by downregulating Bcl-xL. These results concur well with our previous study [11] showing that p38 MAPK mediates TNF-induced endothelial apoptosis via phosphorylation and degradation of $\mathrm{Bcl}-\mathrm{xL}$ in the proteasomes. Lorenzo and coworkers [35] have reported that doxorubicin-induced apoptosis includes a downregulation of Bcl-2 protein and involvement of the mitochondrial pathway. Overexpression of $\mathrm{Bcl}-\mathrm{xL}$ has been observed to protect cardiomyocytes from doxorubicin-provoked apoptosis [50,51], and bcl- 
2/bcl-xL bispecific antisense treatment has been found to sensitize breast carcinoma cells to doxorubicin [52], suggesting an important survival function for Bcl-2 and/or Bcl-xL in cells exposed to doxorubicin.

In earlier studies $[11,12]$ we noted that TNF-induced p38 MAPK-mediated endothelial apoptosis comprised suppression of the MEK/ERK survival pathway. In contrast, our present results suggest that doxorubicin-induced MEK/ERK signaling is proapoptotic, which agrees with other investigations [14-16], and we found that the PI3-K/Akt pathway plays an important role in endothelial cell apoptosis caused by doxorubicin. Of particular interest, our results reveal a previously unreported inhibition of the PI3-K/Akt pathway by p38 MAPK. In addition, we observed that both the caspase-3 activity induced by doxorubicin and the cytotoxicity of this drug were increased by treatment with LY294002, and the inhibition of PI3-K/Akt signaling in $\mathrm{EC}^{\mathrm{DNp} 38}$ amplified those two effects to levels comparable to the levels seen in $\mathrm{EC}^{\mathrm{WT}}$ and $\mathrm{EC}^{\mathrm{CV}}$. Another type of crosstalk between PI3K/Akt and p38 MAPK has been described, where p38 MAPK is inhibited either by Akt 1 via phosphorylation and blocking of MEKK3 [53] or by Akt2 through phosphorylation and inhibition of Apoptosis signal regulating kinase1 (ASK1)[54].

Importantly, we found that $\mathrm{EC}^{\mathrm{DNp} 38}$ displayed a significant increase in Bad Ser112 phosphorylation during doxorubicin-induced apoptosis. This increase was not observed in $\mathrm{EC}^{\mathrm{CV}}$, which suggests that $\mathrm{p} 38$ MAPK prevents phosphorylation of Bad in endothelial cells undergoing apoptosis provoked by doxorubicin. In support of our results, other investigators [50] have reported that phosphorylation of Bad induced by leukemia inhibitory factor blocks doxorubicin-induced apoptosis in myocytes. In our experiments, phosphorylation of both Akt and Bad was stimulated in $\mathrm{EC}^{\mathrm{DNp} 38}$ which implies that the p38 MAPK-effected regulation of Bad phosphorylation is mediated by Akt. Indeed, the doxorubicin-induced increase in Bad phosphorylation was reduced in $\mathrm{EC}^{\mathrm{DNp} 38}$ cotreated with doxorubicin and 
LY294002, indicating that Akt inhibition is central to the p38 MAPK-induced decrease in Bad phosphorylation.

The inhibitory effect of LY294002 on the level of Bad Ser112 phosphorylation is noteworthy, because it indicates that Akt-mediated phosphorylation of Ser136 precedes the phosphorylation of Ser112, the latter of which is assumed to be caused by RSK1, PAK1 or PKA [30-32]. PAK1 has been found to phosphorylate Bad at Ser136 and 112 and to protect fibroblasts and FL5.12 lymphoid progenitor cells from apoptosis [32]. PAK1 can be activated by the small GTPases Rac and Cdc42, and either of those GTPases can be activated by inhibition of PI3-K, which may explain the weak effect of LY294002 treatment on phosphorylation of Bad. It has been suggested that protein phosphatase $2 \mathrm{~A}$ is the major pSer112 phosphatase [55]. Thus, the p38 MAPK-mediated activation of Bad seen during doxorubicin-induced apoptosis may occur directly via protein phosphatase $2 \mathrm{~A}$, as we have previously shown for TNF-induced apoptosis [12], and/or through inhibition of PI3-K/Akt activity.

In summary, it appears that p38 MAPK can transduce a strong death signal in doxorubicin-induced apoptosis by simultaneously decreasing the concentration of Bcl-xL and increasing the activity of Bad.

\section{Acknowledgments}

This study was supported by grants from foundations at Malmö University Hospital, the Alfred Österlund's Foundation, and the Royal Physiographic Society in Lund. We gratefully acknowledge Dr. J. Han (The Scripps Research Institute, La Jolla, CA) for providing the DN Flag-p38 MAPK plasmid. We also thank Paola Circosta for helping with FACS 
analysis, Tommy Andersson for critical reading of the manuscript, and Ms. Patricia Ödman for linguistic revision of the text.

\section{References}

[1] R.B. Weiss, The anthracyclines: Will we ever find a better doxorubicin?, Semin. Oncol. 19 (1992) 670-686.

[2] A.U. Buzdar, C. Marcus, T.L. Smith, G.R. Blumenschein, Early and delayed clinical cardiotoxicity of doxorubicin, Cancer 55 (1985) 2761-2765.

[3] S. Kotamraju, E.A. Konorev, J. Joseph, B. Kalyanaraman, Doxorubicin-induced apoptosis in endothelial cells and cardiomyocytes is ameliorated by nitrone spin traps and ebselen. Role of reactive oxygen and nitrogen species, J. Biol. Chem. 275 (2000) 3358533592.

[4] S. Wang, E. Konorev, S. Kotamraju, J. Joseph, S. Kalivendi, B. Kalyanaraman, Doxorubicin induces apoptosis in normal and tumor cells via distinctly different mechanisms: intermediacy of $\mathrm{H}_{2} \mathrm{O}_{2^{-}}$and p53-dependent pathways, J. Biol. Chem. 279 (2004) 25535-25543.

[5] K.A. Conklin, Coenzyme Q10 for prevention of anthracycline-induced cardiotoxicity, Integr. Cancer Ther. 4 (2005) 110-130.

[6] G. Bocci, K.C. Nicolaou, R.S. Kerbel, Protracted low-dose effects on human endothelial cell proliferation and survival in vitro reveal a selective antiangiogenic window for various chemotherapeutic drugs, Cancer Res. 62 (2002) 6938-6943.

[7] R.M. Schiffelers, G.A. Koning, T.L. ten Hagen, M.H. Fens, A.J. Schraa, A.P. Janssen, R.J. Kok, G. Molema, G. Storm, Anti-tumor efficacy of tumor vasculature targeted liposomal doxorubicin, J. Control. Release 91 (2003) 115-122. 
[8] F. Pastorino, C. Brignole, D. Marimpietri, M. Cilli, C. Gambini, D. Ribatti, R. Longhi, T.M. Allen, A. Corti, M. Ponzoni, Vascular damage and anti-angiogenic effects of tumor vessel-targeted liposomal chemotherapy, Cancer Res. 63 (2003) 7400-7409.

[9] B. Kalyanaraman, J. Joseph, S. Kalivendi, S. Wang, E. Konorev, S. Kotamraju, Doxorubicin-induced apoptosis: implications in cardiotoxicity, Mol. Cell. Biochem. 234235 (2002) 119-124.

[10] S. Wu, Y.S. Ko, M.S. Teng, Y.L. Ko, L.A Hsu, C. Hsueh, Y.Y. Chou, C.C. Liew, Y.S. Lee, Adriamycin-induced cardiomyocyte and endothelial cell apoptosis: in vitro and in vivo studies, J. Mol. Cell. Cardiol. 34 (2002) 1595-1607.

[11] S. Grethe, M.P.S. Ares, T. Andersson, M.I. Pörn-Ares, p38 MAPK mediates TNFinduced apoptosis in endothelial cells via phosphorylation and downregulation of $\mathrm{Bcl}-\mathrm{x}_{\mathrm{L}}$, Exp. Cell Res. 298 (2004) 632-642.

[12] S. Grethe, M.I. Pörn-Ares, p38 MAPK mediates inhibition of Bad via PP2A-dependent suppression of the MEK1/2-ERK1/2 survival pathway in TNF- $\alpha$-induced endothelial apoptosis, Cell. Signal. 18 (2006) 531-540.

[13] W. Zhang, H.T. Liu, MAPK signal pathways in the regulation of cell proliferation in mammalian cells, Cell Res. 12 (2002) 9-18.

[14] S. Guise, D. Braguer, G. Carles, A. Delacourte, C. Briand, Hyperphosphorylation of tau is mediated by ERK activation during anticancer drug-induced apoptosis in neuroblastoma cells, J. Neurosc. Res. 63 (2001) 257-267.

[15] D. Tang, D. Wu, A. Hirao, J.M. Lahti, L. Liu, B. Mazza, V.J. Kidd, T.W. Mak, A.J. Ingram, ERK activation mediates cell cycle arrest and apoptosis after DNA damage independently of p53, J. Biol. Chem. 277 (2002) 12710-12717. 
[16] P.Y. Yeh, S.E. Chuang, K.H. Yeh, Y.C. Song, L.L. Chang, A.L. Cheng, Phosphorylation of p53 on Thr55 by ERK2 is necessary for doxorubicin-induced p53 activation and cell death, Oncogene 23 (2004) 3580-3588.

[17] L. Stephens, K. Anderson, D. Stokoe, H. Erdjument-Bromage, G.F. Painter, A.B. Holmes, P.R. Gaffney, C.B. Reese, F. McCormick, P. Tempst, J. Coadwell, P.T. Hawkins, Protein kinase B kinases that mediate phosphatidylinositol 3,4,5-trisphosphate-dependent activation of protein kinase B, Science 279 (1998) 710-714.

[18] A. Toker, A.C. Newton, Akt/Protein Kinase B is regulated by autophosphorylation at the hypothetical PDK-2 site, J. Biol. Chem. 275 (2000) 8271-8274.

[19] S. Persad, S. Attwell, V. Gray, N. Mawji, J.T. Deng, D. Leung, J. Yan, J. Sanghera, M.P. Walsh, S. Dedhar, Regulation of Protein Kinase B/Akt-Serine 473 phosphorylation by integrin-linked kinase, J. Biol. Chem. 276 (2001) 27462-27469.

[20] M.H. Cardone, N. Roy, H.R. Stennicke, G.S. Salvesen, T.F. Franke, E. Stanbridge, S. Frisch, J.C. Reed, Regulation of cell death protease caspase-9 by phosphorylation, Science 282 (1998) 1318-1321.

[21] S.R. Datta, H. Dudek, X. Tao, S. Masters, H. Fu, Y. Gotoh, M.E. Greenberg, Akt phosphorylation of BAD couples survival signals to the cell-intrinsic death machinery, Cell 91 (1997) 231-241.

[22] A. Brunet, A. Bonni, M.J. Zigmond, M.Z. Lin, P. Juo, L.S. Hu, M.J. Anderson, K.C. Arden, J. Blenis, M.E. Greenberg, Akt promotes cell survival by phosphorylating and inhibiting a Forkhead transcription factor, Cell 96 (1999) 857-868.

[23] M. Pap, G.M. Cooper, Role of glycogen synthase kinase-3 in the phosphatidylinositol 3-Kinase/Akt cell survival pathway, J. Biol. Chem. 273 (1998) 19929-19932.

[24] L.P. Kane, V.S. Shapiro, D. Stokoe, A. Weiss, Induction of NFkB by the Akt/PKB kinase, Curr. Biol. 9 (1999) 601-604. 
[25] P. Secchiero, A. Gorelli, E. Carnevale, D. Milani, A. Pandolfi, D. Zella, G. Zauli, TRAIL promotes the survival and proliferation of primary human vascular endothelial cells by activating the Akt and ERK pathways, Circulation 107 (2003) 2250-2256.

[26] K. Takeuchi, F. Ito, Suppression of adriamycin-induced apoptosis by sustained activation of the phosphatidylinositol-3'-OH kinase-Akt pathway, J. Biol. Chem. 279 (2004) 892-900.

[27] J. Downward, How BAD phosphorylation is good for survival, Nat. Cell Biol. 1 (1999) E33-E35.

[28] E. Yang, J. Zha, J. Jockel, L.H. Boise, C.B. Thompson, S.J. Korsmeyer, Bad, a heterodimeric partner for Bcl-XL and Bcl-2, displaces Bax and promotes cell death, Cell 80 (1995) 285-291.

[29] X.M. Zhou, Y. Liu, G. Payne, R.J. Lutz, T. Chittenden, Growth factors inactivate the cell death promoter BAD by phosphorylation of its BH3 domain on Ser ${ }^{155}$, J. Biol. Chem. 275 (2000) 25046-25051.

[30] H. Harada, B. Becknell, M. Wilm, M. Mann, L.J. Huang, S.S. Taylor, J.D. Scott, S.J. Korsmeyer, Phosphorylation and inactivation of BAD by mitochondria-anchored protein kinase A, Mol. Cell 3 (1999) 413-422.

[31] A. Shimamura, B.A. Ballif, S.A. Richards, J. Blenis, Rsk1 mediates a MEK-MAP kinase cell survival signal, Curr. Biol. 10 (2000) 127-135.

[32] A. Schürmann, A.F. Mooney, L.C. Sanders, M.A. Sells, H.G. Wang, J.C. Reed, G.M. Bokoch, p21-activated kinase 1 phosphorylates the death agonist Bad and protects cells from apoptosis, Mol. Cell Biol. 20 (2000) 453-461.

[33] H. Harada, J.S. Andersen, M. Mann, N. Terada, S.J. Korsmeyer, p70S6 kinase signals cell survival as well as growth, inactivating the pro-apoptotic molecule BAD, Proc. Natl. Acad. Sci. USA 98 (2001) 9666-9670. 
[34] C.J. Edgell, C.C. McDonald, J.B. Graham, Permanent cell line expressing human factor VIII-related antigen established by hybridization, Proc. Natl. Acad. Sci. USA 80 (1983) $3734-3737$.

[35] E. Lorenzo, C. Ruiz-Ruiz, A.J. Quesada, G. Hernandez, A. Rodriguez, A. Lopez-Rivas, J.M. Redondo, Doxorubicin induces apoptosis and CD95 gene expression in human primary endothelial cells through a p53-dependent mechanism, J. Biol. Chem. 277 (2002) 10883-10892.

[36] A. Follenzi, L.E. Ailles, S. Bakovic, M. Geuna, L. Naldini, Gene transfer by lentiviral vectors is limited by nuclear translocation and rescued by HIV-1 pol sequences, Nat. Genet. 25 (2000) 217-222.

[37] J. Han, J.D. Lee, L. Bibbs, R.J. Ulevitch, A MAP kinase targeted by endotoxin and hyperosmolarity in mammalian cells, Science 265 (1994) 808-811.

[38] C. Bardella, B. Costa, P. Maggiora, S. Patane, M. Olivero, G.N. Ranzani, M. De Bortoli, P.M. Comoglio, M.F. Di Renzo, Truncated RON tyrosine kinase drives tumor cell progression and abrogates cell-cell adhesion through E-cadherin transcriptional repression, Cancer Res. 64 (2004) 5154-5161.

[39] L. Gianni, J.L. Zweier, A. Levy, C.E. Myers, Characterization of the cycle of ironmediated electron transfer from Adriamycin to molecular oxygen, J. Biol. Chem. 260 (1985) 6820-6826.

[40] J. Vasquez-Vivar, P. Martasek, N. Hogg, B.S. Masters, K.A. Pritchard, Jr, B. Kalyanaraman, Endothelial nitric oxide synthase-dependent superoxide generation from adriamycin, Biochemistry 36 (1997) 11293-11297.

[41] S. Hashimoto, Y. Gon, K. Matsumoto, I. Takeshita, T. Horie, N-acetylcysteine attenuates TNF-alpha-induced p38 MAP kinase activation and p38 MAP kinase-mediated 
IL-8 production by human pulmonary vascular endothelial cells, Br. J. Pharmacol. 132 (2001) 270-276.

[42] R.J. Gum, M.M. McLaughlin, S. Kumar, Z. Wang, M.J. Bower, J.C. Lee, J.L. Adams, G.P Livi, E.J. Goldsmith, P.R. Young, Acquisition of sensitivity of stress-activated protein kinases to the p38 inhibitor, SB203580, by alteration of one or more amino acids within the ATP binding pocket, J. Biol. Chem. 273 (1998) 15605-15610.

[43] T. Panaretakis, E. Laane, K. Pokrovskaja, A.C. Björklund, A. Moustakas, B. Zhivotovsky, M. Heyman, M.C. Shoshan, D. Grander, Doxorubicin requires the sequential activation of caspase-2, protein kinase $\mathrm{C} \delta$, and c-Jun $\mathrm{NH}_{2}$-terminal kinase to induce apoptosis, Mol. Biol. Cell 16 (2005) 3821-3831.

[44] K. Breitschopf, J. Haendeler, P. Malchow, A.M. Zeiher, S. Dimmeler, Posttranslational modification of Bcl-2 facilitates its proteasome-dependent degradation: molecular characterization of the involved signaling pathway, Mol. Cell Biol. 20 (2000) 1886-1896.

[45] R. Sanchez-Prieto, J.M. Rojas, Y. Taya, J.S. Gutkind, A role for the p38 mitogenactivated protein kinase pathway in the transcriptional activation of p53 on genotoxic stress by chemotherapeutic agents, Cancer Res. 60 (2000) 2464-2472.

[46] Y.J. Kang, Z.X. Zhou, G.W. Wang, A. Buridi, J.B. Klein, Suppression by metallothionein of doxorubicin-induced cardiomyocyte apoptosis through inhibition of p38 mitogen-activated protein kinases, J. Biol. Chem. 275 (2000) 13690-13698.

[47] C. Poizat, P.L. Puri, Y. Bai, L. Kedes, Phosphorylation-dependent degradation of p300 by doxorubicin-activated p38 mitogen-activated protein kinase in cardiac cells, Mol. Cell Biol. 25 (2005) 2673-2687.

[48] A.A. Liem, M.V. Appleyard, M.A. O'Neill, T.R. Hupp, M.P. Chamberlain, A.M. Thompson, Doxorubicin and vinorelbine act independently via p53 expression and p38 activation respectively in breast cancer cell lines, Br. J. Cancer 88 (2003) 1281-1284. 
[49] Y. Zhao, H. You, Y. Yang, L. Wei, X. Zhang, L. Yao, D. Fan, Q. Yu, Distinctive regulation and function of PI 3K/Akt and MAPKs in doxorubicin-induced apoptosis of human lung adenocarcinoma cells, J. Cell. Biochem. 91 (2004) 621-632.

[50] S. Negoro, H. Oh, E. Tone, K. Kunisada, Y. Fujio, K. Walsh, T. Kishimoto, K. Yamauchi-Takihara, Glycoprotein 130 regulates cardiac myocyte survival in doxorubicininduced apoptosis through phosphatidylinositol 3-kinase/Akt phosphorylation and BclxL/caspase-3 interaction, Circulation 103 (2001) 555-561.

[51] K. Kunisada, E. Tone, S. Negoro, Y. Nakaoka, Y. Oshima, T. Osugi, M. Funamoto, M. Izumi, Y. Fujio, H. Hirota, K. Yamauchi-Takihara, Bcl-xL reduces doxorubicin-induced myocardial damage but fails to control cardiac gene downregulation, Cardiovasc. Res. 53 (2002) 936-943.

[52] A.P. Simoes-Wüst, T. Schürpf, J. Hall, R.A. Stahel, U. Zangemeister-Wittke, Bcl2/bcl-xL bispecific antisense treatment sensitizes breast carcinoma cells to doxorubicin, paclitaxel and cyclophosphamide, Breast Cancer Res. Treat. 76 (2002) 157-166.

[53] J.P. Gratton, M. Morales-Ruiz, Y. Kureishi, D. Fulton, K. Walsh, W.C. Sessa, Akt down-regulation of p38 signaling provides a novel mechanism of vascular endothelial growth factor-mediated cytoprotection in endothelial cells, J. Biol. Chem. 276 (2001) 30359-30365.

[54] Z. Yuan, R.I. Feldman, G.E. Sussman, D. Coppola, S.V. Nicosia, J.Q. Cheng, AKT2 inhibition of cisplatin-induced JNK/p38 and Bax activation by phosphorylation of ASK1: implication of AKT2 in chemoresistance, J. Biol. Chem. 278 (2003) 23432-23440. [55] C.W. Chiang, C. Kanies, K.W. Kim, W.B. Fang, C. Parkhurst, M. Xie, T. Henry, E. Yang, Protein phosphatase 2A dephosphorylation of phosphoserine 112 plays the gatekeeper role for BAD-mediated apoptosis, Mol. Cell Biol. 23 (2003) 6350-6362. 


\section{Figure legends}

Fig. 1. Caspase-3 activation, cell death and p38 MAPK phosphorylation caused by doxorubicin in EA.hy926 cells. (A) and (B) $\mathrm{EC}^{\mathrm{WT}}, \mathrm{EC}^{\mathrm{CV}}$ and $\mathrm{EC}^{\mathrm{DNp} 38}$ were treated with increasing concentrations of doxorubicin for $24 \mathrm{~h}$, and then subjected to Western blotting. Cleavage of PARP (116 kDa) and production of the $85-\mathrm{kDa}$ fragment were detected with an anti-PARP mAb. (B) The optical density (OD) of PARP bands on Western blots was scanned, and the results are shown as means of 4-8 experiments + SD (for $n<5)$ or SEM. (C) Cells were treated with doxorubicin $(0.5 \mu \mathrm{g} / \mathrm{ml})$ for $21 \mathrm{~h}$ and caspase- 3 activity was measured as cleavage of DEVD-amc in a fluorescence plate reader assay. The level of activity induced by doxorubicin is shown as fold increase compared to untreated cells, and the values given are means + SD or SEM of 3-5 experiments. (D) Cells were treated with doxorubicin $(0.5 \mu \mathrm{g} / \mathrm{ml})$ for $24 \mathrm{~h}$ and then harvested for trypan blue exclusion. The illustrated data represents means of six separate experiments + SEM. The black, grey, and white bars in diagrams $\mathrm{B}, \mathrm{C}$, and $\mathrm{D}$ represent $\mathrm{EC}^{\mathrm{WT}}, \mathrm{EC}^{\mathrm{CV}}$, and $\mathrm{EC}^{\mathrm{DNp} 38}$, respectively. $(\mathrm{E})$ $\mathrm{EC}^{\mathrm{WT}}$ were treated with increasing concentrations of doxorubicin for $24 \mathrm{~h}$ and thereafter subjected to Western blotting with an anti-phospho-p38 MAPK Ab to detect the phosphorylated form of p38 MAPK (p38-P). The PVDF membrane was subsequently stripped and reprobed with an Ab against total cellular p38 MAPK as a loading control. The illustrated blot is representative of three independent experiments.

Fig. 2. Doxorubicin-induced endothelial apoptosis is impeded by inhibition of p38 MAPK with SB203580. Cells were exposed to doxorubicin $(0.5 \mu \mathrm{g} / \mathrm{ml})$ for $24 \mathrm{~h}$ (A and C) or $21 \mathrm{~h}$ (B) and were or were not cotreated with SB203580 $(5 \mu \mathrm{M})$; some dishes of cells were treated solely with SB203580. (A) Cleavage of PARP and production of the $85-\mathrm{kDa}$ 
fragment were detected with an anti-PARP mAb. The Western blot shown is representative of five separate experiments with similar results. The PARP bands from Western blots were scanned for OD, and the illustrated data represents the ratios of 85-kDa PARP to total (116 kDa plus $85 \mathrm{kDa}$ ) calculated for five separate experiments + SEM. (B) Caspase-3 activity was measured as cleavage of DEVD-amc using a fluorescence plate reader assay. The activity induced by doxorubicin was assigned a value of 1 and all other responses were calculated in relation to this value. The results given represent means + SEM of five experiments. (C) Cells were processed for trypan blue exclusion and the illustrated data represent means $+\mathrm{SD}$ of three independent experiments.

Fig. 3. The role of other MAPKs and Akt in doxorubicin-induced endothelial cell apoptosis. Cells were or were not pretreated for $1 \mathrm{~h}$ with $10 \mu \mathrm{M}$ SP600125, $25 \mu \mathrm{M}$ PD98059, or 10 $\mu \mathrm{M}$ LY294002 before exposure to $0.5 \mu \mathrm{g} / \mathrm{ml}$ doxorubicin for $21 \mathrm{~h}(\mathrm{~A})$ or $24 \mathrm{~h}(\mathrm{~B})$, or they were treated solely with one of the inhibitors. (A) Caspase-3 activity was measured as cleavage of DEVD-amc, and the activity in untreated cells was assigned a value of 1 and all other responses were calculated in relation to this value. The results given represent means + SD (for $\mathrm{n}<5$ ) or SEM of 3-7 experiments. (B) Viability of the cells was assessed by trypan blue exclusion, and the illustrated data represent means + SD or SEM of 3-6 separate experiments. (C) $\mathrm{EC}^{\mathrm{CV}}$ and $\mathrm{EC}^{\mathrm{DNp} 38}$ were treated with the indicated concentrations of doxorubicin for $24 \mathrm{~h}$ and thereafter lysed and subjected to Western blotting with an antiphospho-ERK Ab to detect the phosphorylated form of ERK (ERK-P). The PVDF membrane was subsequently stripped and reprobed with an Ab against total cellular ERK. The blots shown are representative of three independent experiments. 
Fig. 4. Downregulation of Bcl-xL in endothelial cells treated with doxorubicin is mediated by p38 MAPK. $\mathrm{EC}^{\mathrm{CV}}$ and $\mathrm{EC}^{\mathrm{DNp} 38}$ were exposed to increasing concentrations of doxorubicin for $24 \mathrm{~h}$. (A) Levels of Bcl-xL in the doxorubicin-treated cells were analyzed by Western blotting with an anti-Bcl-xL Ab. The PVDF membranes were subsequently stripped and reprobed with an anti- $\alpha$-tubulin Ab. (B) The Bcl-xL and $\alpha$-tubulin bands from western blots of samples treated with or without $0.5 \mu \mathrm{g} / \mathrm{ml}$ doxorubicin were scanned for $\mathrm{OD}$, and the results shown are calculated ratios $\left(\mathrm{OD}_{\mathrm{Bcl-xL}} / \mathrm{OD}_{\text {tubulin }}\right)$ from 3-5 separate experiments. The black and white bars in diagram $\mathrm{B}$ represent $\mathrm{EC}^{\mathrm{CV}}$ and $\mathrm{EC}^{\mathrm{DNp} 38}$, respectively.

Fig. 5. The activity of Bad in endothelial cells is regulated by p38 MAPK via inhibition of Akt. (A) $\mathrm{EC}^{\mathrm{CV}}$ and $\mathrm{EC}^{\mathrm{DNp} 38}$ cells were either left untreated or exposed to $0.5 \mu \mathrm{g} / \mathrm{ml}$ doxorubicin for $24 \mathrm{~h}$. Western blotting was performed with an anti-Bad Ab specific for phosphorylation at Ser112 (Bad-P), and the PVDF membranes were subsequently stripped and reprobed with and anti-total $\mathrm{Bad} \mathrm{Ab}(\mathrm{Bad})$. The blots shown are representative of five separate experiments. The Bad-P and Bad bands were scanned for OD, and the results shown are calculated ratios $\left(\mathrm{OD}_{\mathrm{Bad}-\mathrm{P}} / \mathrm{OD}_{\mathrm{Bad}}\right)$ from five independent experiments $\left(\mathrm{EC}^{\mathrm{CV}}\right.$, black bars; $\mathrm{EC}^{\mathrm{DNp} 38}$, white bars. (B) Cells were treated with the indicated concentrations of doxorubicin for $24 \mathrm{~h}$ and then analyzed by Western blotting with an anti-phospho-Akt Ab to detect the activated form of Akt (Akt-P). Thereafter, the PVDF membrane was stripped and reprobed with an Ab against total cellular Akt. The Akt-P and Akt bands from samples treated with $0.5 \mu \mathrm{g} / \mathrm{ml}$ doxorubicin were scanned for OD, and the results shown are calculated ratios $\left(\mathrm{OD}_{\mathrm{Akt}-\mathrm{P}} / \mathrm{OD}_{\mathrm{Akt}}\right)$ from 4-6 separate experiments. $(\mathrm{C}) \mathrm{EC}^{\mathrm{DNp} 38}$ cells were exposed to $0.5 \mu \mathrm{g} / \mathrm{ml}$ doxorubicin fort $18 \mathrm{~h}$; some dishes of cells were pretreated with LY294002 $(10 \mu \mathrm{M})$ before exposure to doxorubicin. Western blots were analyzed with an 
anti-Bad Ab specific for phosphorylation at Ser112 or anti-total Bad Ab. The blots shown are representative of three separate experiments. 
A

Fig. 1

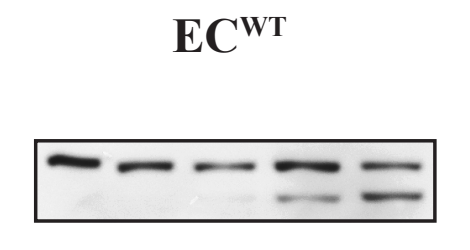

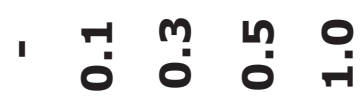
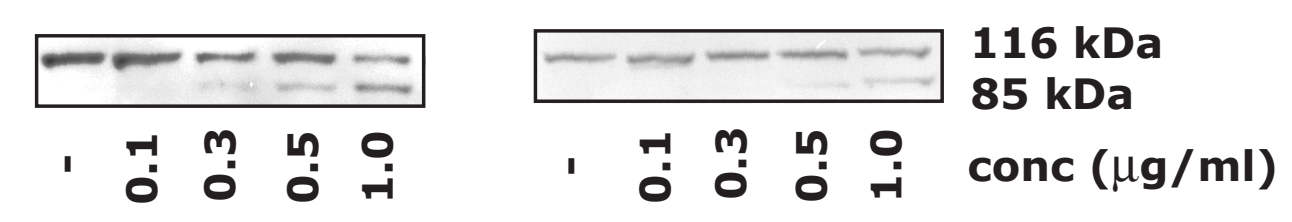

B

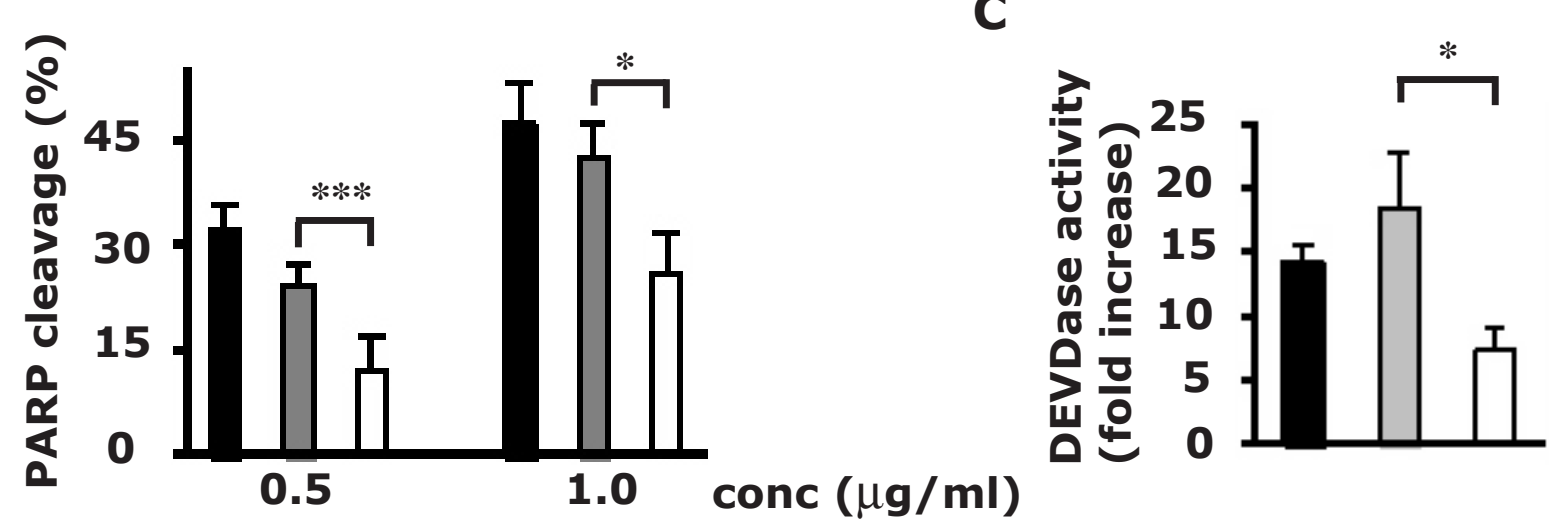

D

E
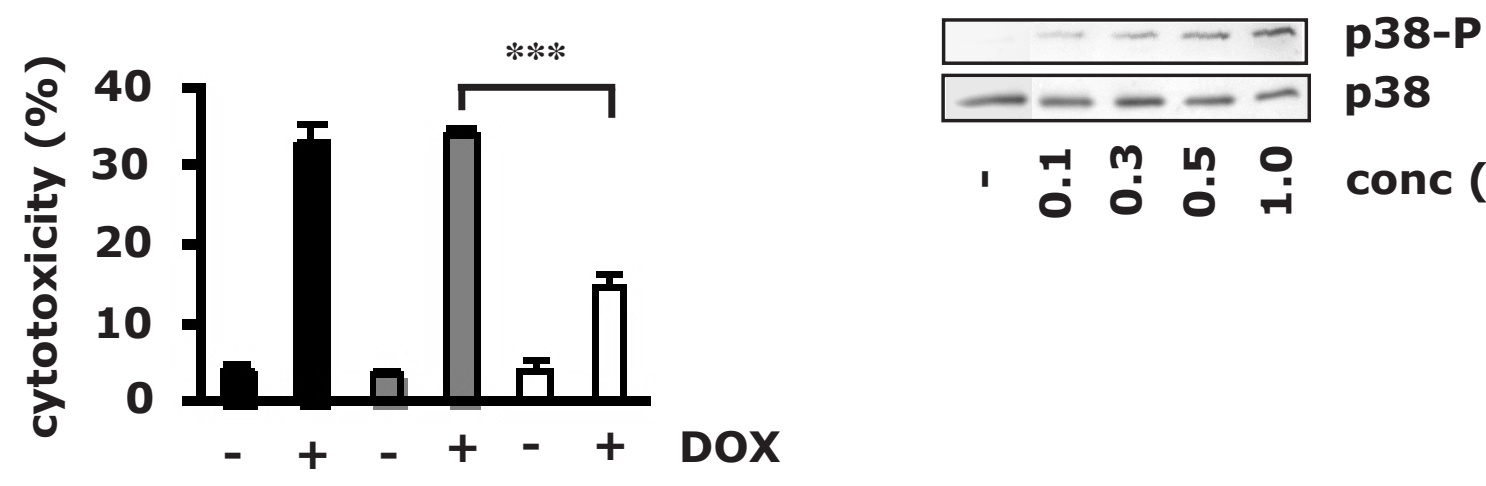

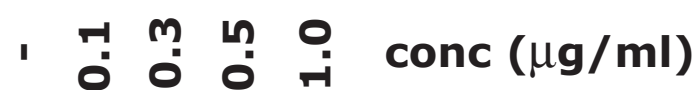


Fig. 2

A
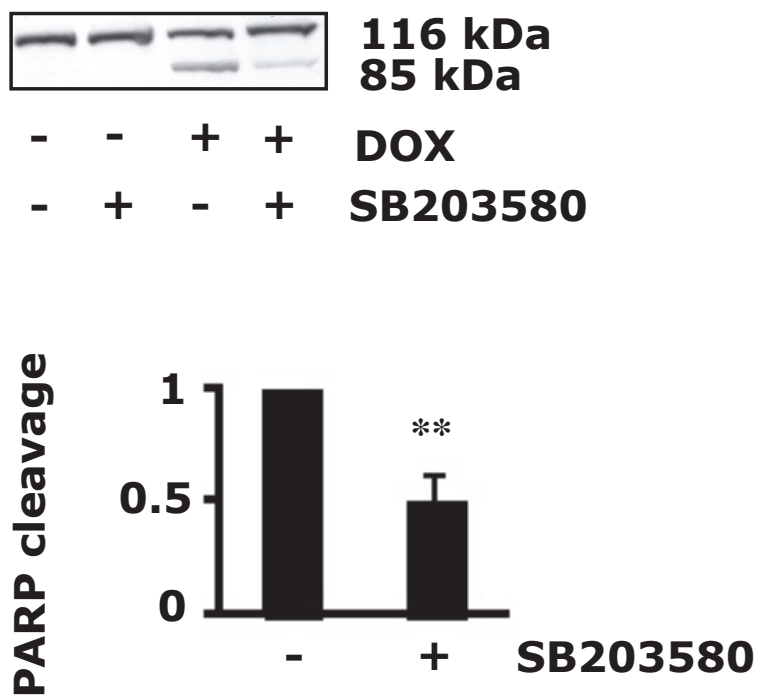

B

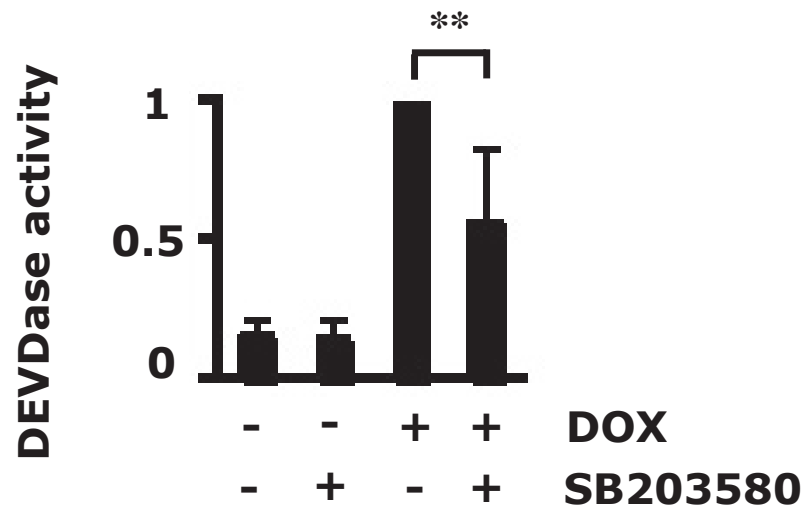

C

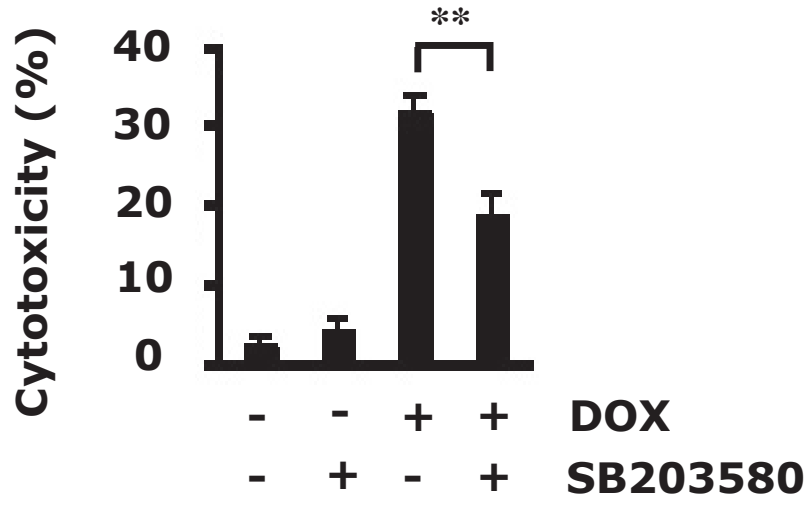


Fig.3

A
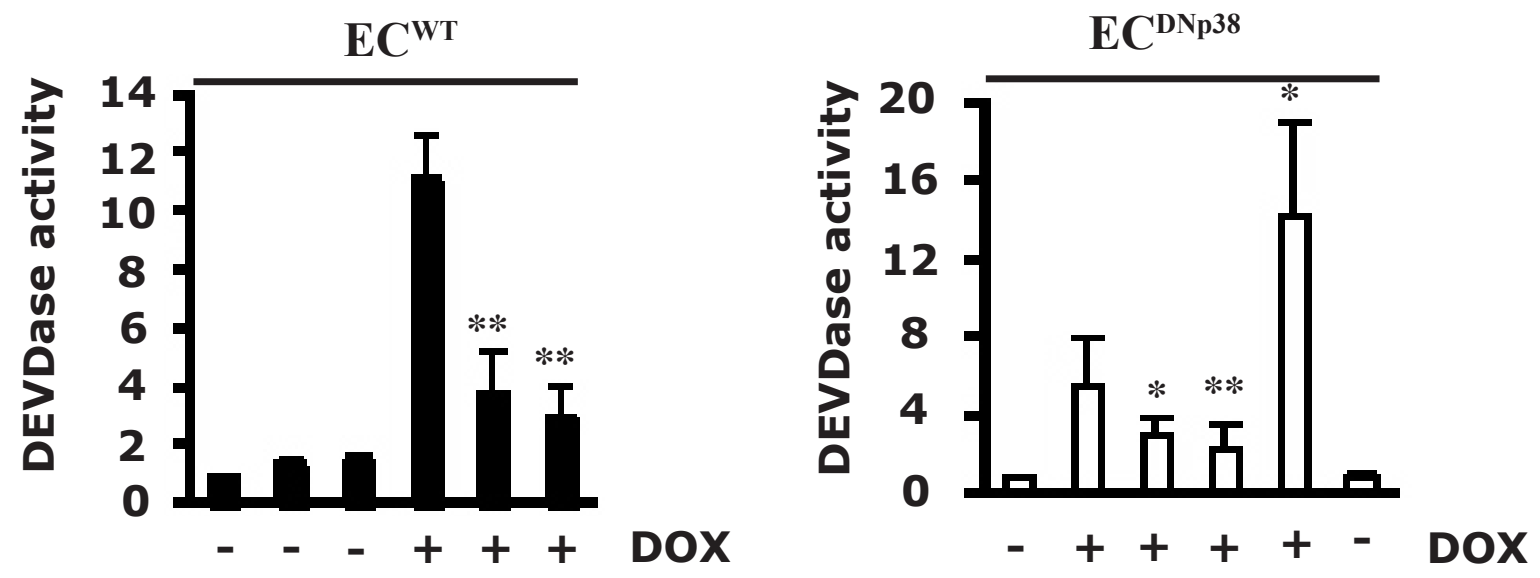

- + - + - SP600125

- - + - - - SP600125

- + + - + PD98059

- - - + - - PD98059

- - - + + LY294002

B
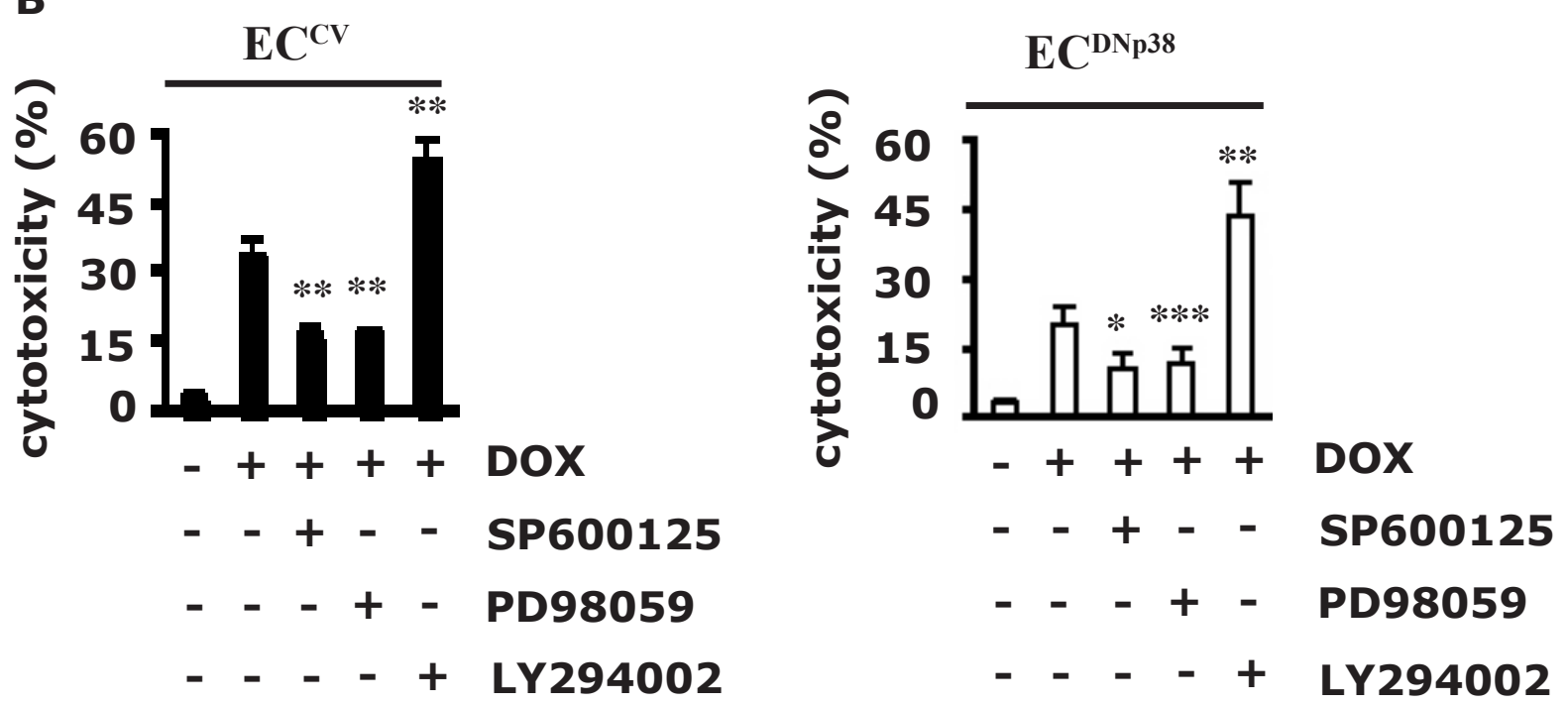

C

$\mathrm{EC}^{\mathrm{CV}}$

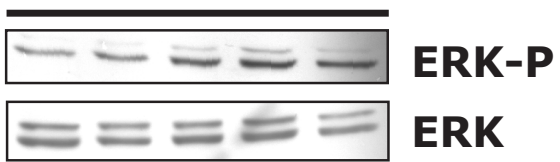

EC $^{\text {DNp38 }}$

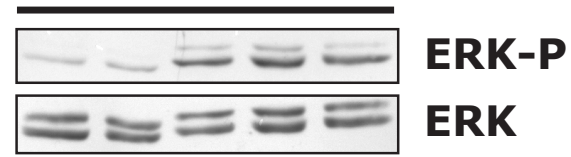

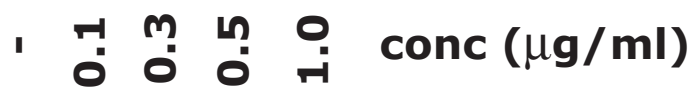

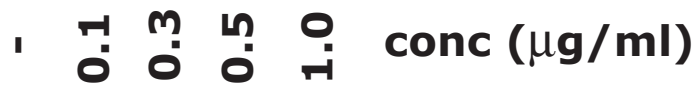


Fig. 4

A
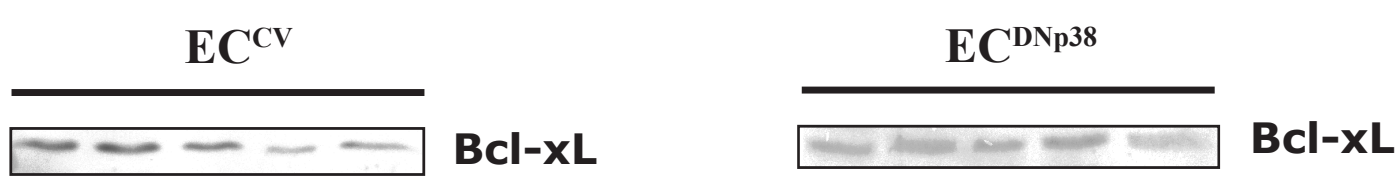

$\because-\cdots-\infty$ tubulin

$w-\infty=\infty$ tubulin

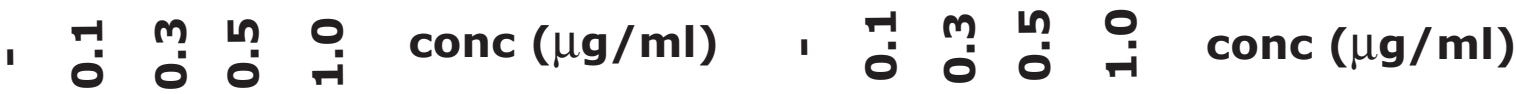

B

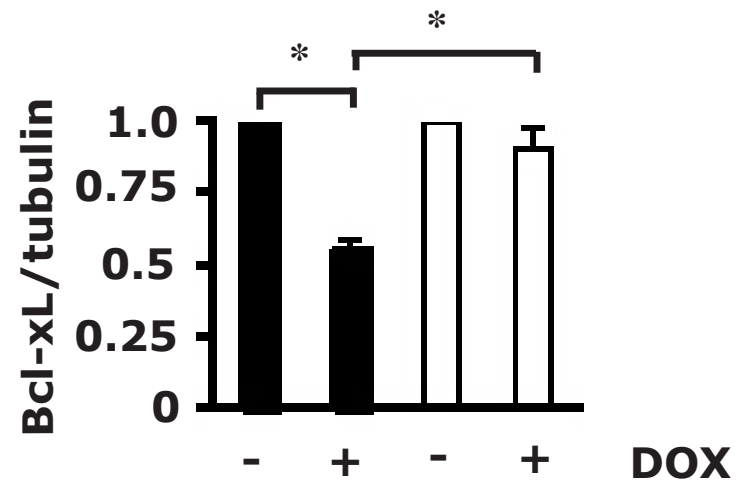


A

Fig. 5
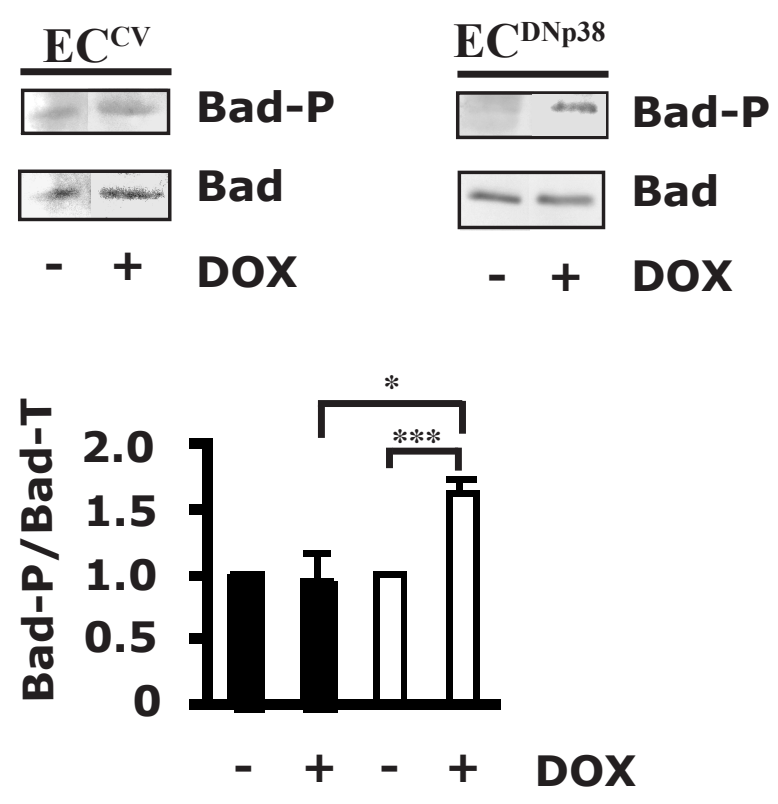

B
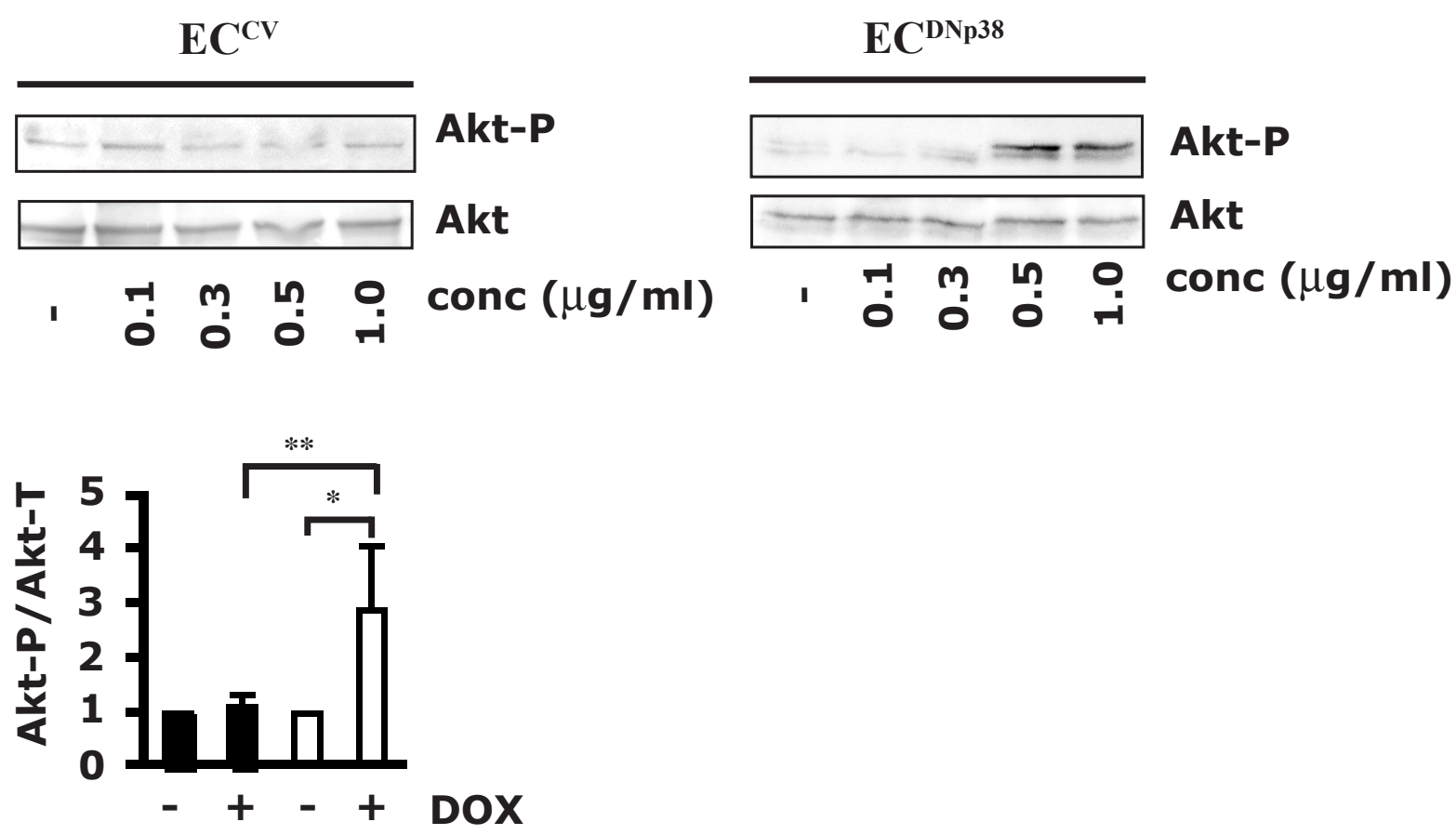

C

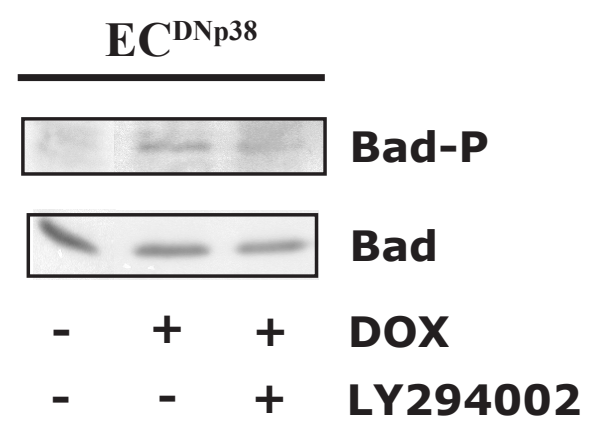

